\title{
Programação, Robôs e Aprendizagem Criativa por meio de Cenários: um estudo exploratório
}

\author{
Marleny Luque Carbajal ${ }^{1}$, M. Cecília C. Baranauskas ${ }^{1}$ \\ ${ }^{1}$ Instituto de Computação - Universidade Estadual de Campinas (UNICAMP) \\ Caixa Postal 6.176 - 13.083 - 970 - Campinas - SP - Brasil \\ marleny.carbajalestudents.ic.unicamp.br, cecilialic.unicamp.br
}

\begin{abstract}
In an increasingly technological world of constant change, encouraging the development of skills such as creativity is becoming more and more important. Creative people are curious and enjoy exploring ideas, so they are more innovative in problem solving. Literature has discussed how to encourage creativity in the classroom and presented the emerging concept of "creative learning", which attempts to understand, experiment and define which methodologies and learning environments are capable of promoting creativity. In this paper, we explore and discuss the use of Tangible User Interfaces to facilitate creative learning in the context of computer programming and how to design activities to promote it within the school environment.
\end{abstract}

Resumo. Em um mundo cada vez mais tecnológico e de constantes mudanças, incentivar o desenvolvimento de habilidades como a criatividade está se tornando cada vez mais importante. Pessoas criativas são curiosas e gostam de explorar ideias, por isso são mais inovadoras na resolução de problemas. A literatura tem discutido maneiras de incentivar a criatividade em sala de aula e apresentado o conceito emergente da "aprendizagem criativa", que tenta entender, experimentar e caracterizar metodologias e ambientes de aprendizagem capazes de promover a criatividade. Neste artigo, exploramos e discutimos o uso de Interfaces Tangíveis para facilitar a aprendizagem criativa no contexto da programação de computadores e como projetar atividades que a facilitem dentro do ambiente escolar.

\section{Introdução}

A capacidade de gerar conhecimento, pensar e agir de maneira criativa estão se tornando mais importantes do que a capacidade de memorizar informação existente. No entanto, esse tipo de habilidade não pode ser adquirido com uma educação convencional, com a transferência de ideias e técnicas existentes de docentes aos estudantes. É necessário um novo paradigma; alguns autores acreditam que esse paradigma é o da "aprendizagem criativa" [Iba \& Miyake 2010]. O especialista SeftonGreen, descreve a aprendizagem criativa como o ensino que permite aos estudantes usar sua imaginação, ter ideias, gerar múltiplas soluções possíveis para os problemas, se comunicar em uma variedade de mídias e, em geral, pensar "fora da caixa" [SeftonGreen \& Bresler 2011]. As pesquisas de Resnick sobre aprendizagem criativa difundem o princípio de aprender por toda a vida por meio de projetos e experiências que permitam aos estudantes explorar e deixar de lado as atividades estanques [Resnick 2006]. 
VII Congresso Brasileiro de Informática na Educação (CBIE 2018)

Anais do XXIX Simpósio Brasileiro de Informática na Educação (SBIE 2018)

Para encontrar novas maneiras de cultivar o pensamento criativo e criar ferramentas que deem suporte à aprendizagem criativa é importante explorar a natureza colaborativa e improvisada da criatividade humana. Os teóricos da enação, uma nova vertente da ciência cognitiva, entendem que a cognição e a criatividade sempre emergem através de uma interação em tempo real e improvisada com o ambiente e outros agentes nesse ambiente [Stewart et al. 2010, Varela et al. 2017]. O "conhecimento enativo" se refere a um tipo de conhecimento armazenado sob a forma de respostas motoras e adquirido pelo ato de fazer [Bruner et al. 1966]. Este tipo de conhecimento pode ser considerado natural e intuitivo, pois é baseado na experiência e no envolvimento do corpo. Exemplos deste tipo de conhecimento são atividades como tocar um instrumento musical ou balançar o braço para jogar um videogame de tênis de mesa. As Interfaces Tangíveis (TUIs - Tangible User Interfaces) [Ishii \& Ullmer 1997] se apresentam como uma forma de envolver a interação com o mundo físico para apoiar as crianças durante o processo de desenvolvimento da inteligência e da criatividade. As TUIs permitem que o usuário possa interagir com a informação digital por meio da manipulação de um objeto físico diferente dos periféricos tradicionais como o teclado ou o mouse. No contexto educacional, foi demonstrado [Xu 2005] que as interfaces de programação tangíveis são especialmente adequadas para introduzir as crianças na programação porque tornam os conceitos mais acessíveis. Alguns estudos mostraram que o ensino de programação pode ter um efeito positivo sobre o desempenho das crianças, não só em áreas como matemática e ciências, mas também nas habilidades de linguagem, criatividade, interação social e emocional [Clements 1999]. Por outro lado, o estudo realizado por Benitti (2012) mostrou que a robótica educativa tem um enorme potencial como ferramenta de aprendizagem, incluindo o apoio ao ensino de disciplinas que não estão intimamente relacionadas com o campo da robótica. A revisão sistemática de Avila et al. (2017) revelou que os kits da empresa LEGO lideram os kits para o ensino de robótica na escola e ainda não é tão frequente a utilização de placas controladoras do tipo hardware livre, como Arduino, ou equipamentos do tipo mini-pc como Raspberry PI.

Considerando o que foi exposto, neste trabalho propomos o ambiente "TaPrEC + mBot" de programação tangível como uma alternativa baseada em hardware livre para apoiar a aprendizagem de programação e robótica na escola de forma criativa. Assim, este artigo está organizado nas seguintes seções: na seção 2 a seguir, apresentamos alguns trabalhos relacionados a nosso projeto; na seção 3 detalhamos os aspectos tecnológicos do ambiente "TaPrEC+mBot"; na seção 4 descrevemos a metodologia utilizada para a realização do Estudo de Caso no qual experimentamos o ambiente "TaPrEC+mBot"; na seção 5 apresentamos os principais resultados obtidos no Estudo de Caso realizado com docentes e estudantes de ensino fundamental; e finalmente na seção 6 apresentamos as considerações finais.

\section{Trabalhos Relacionados}

A seguir ilustramos alguns trabalhos que abordam cenários de programação tangível que possuem uma saída física para a execução do programa tangível: i) o sistema Tangible Programming Bricks [McNerney 1999] possui peças LEGO que tinham incorporado um microprocessador com um interpretador Logo e uma memória programável para armazenar um programa Logo. Para a construção de programas, as peças deviam ser empilhadas acima ou abaixo de outra. Os programas tangíveis podiam controlar carros e trens de brinquedo; ii) a linguagem Tern [Horn 2007] permite criar programas tangíveis 
VII Congresso Brasileiro de Informática na Educação (CBIE 2018)

Anais do XXIX Simpósio Brasileiro de Informática na Educação (SBIE 2018)

conectando blocos de madeira em forma de peças de quebra-cabeça que possuem símbolos TopCode colados na superfície. As crianças utilizam uma câmera para capturar a imagem do programa tangível para transferir as instruções do programa para um laptop onde é processado utilizando visão computacional. Os programas são utilizados para controlar robôs virtuais ou robôs como o LEGO Mindstorms RCX ou o iRobot Create; iii) Robo-Blocks [Sipitakiat \& Nusen 2012] tem blocos que podem ser conectados magneticamente para controlar um robô através de instruções simples como mover para frente, mover para trás, virar à esquerda e virar à direita. Cada bloco possui um LED que acende quando está sendo executado, isto permite ao usuário depurar o programa criado.

Os ambientes apresentados apoiam a construção física de um programa de computador conectando ou empilhando peças que representam uma ação que é executada por um robô. Os objetos tangíveis dos ambientes utilizam diferentes tipos de tecnologia: microprocessadores (Tangible Programming Bricks), microcontroladores (Robo-Blocks) e visão computacional (Tern). O ambiente Tern utiliza códigos de visão computacional que possibilitam diminuir o custo da criação dos objetos tangíveis, mas requer conhecimento da linguagem de programação Java. Por outro lado, os robôs utilizados pelos ambientes Tern, Tangible Programming Bricks e Robo-Blocks foram montados utilizando peças LEGO e placas eletrônicas que permitem conectar componentes externos. Como foi constatado na revisão sistemática sobre robótica na escola do Benitti (2012), um pequeno número de pesquisas envolve kits de baixo custo, relatando que 90\% dos projetos utilizavam LEGO. Pensando nas desvantagens encontradas em termos de flexibilidade e facilidade de criação de objetos tangíveis dos trabalhos relacionados, assim como na necessidade de um robô de hardware livre, fácil montagem, compatível com diferentes módulos eletrônicos e economicamente mais acessíveis; integramos o ambiente TaPrEC e o robô mBot para fornecer uma alternativa de fácil customização e versátil para o ensino de robótica e programação na escola.

\section{Ambiente de programação "TaPrEC+mBot"}

"TaPrEC+mBot" é constituído pelo ambiente TaPrEC de programação tangível e o kit educacional mBot que tem a forma de um carrinho e foi utilizado para representar a saída física dos programas tangíveis. A seguir detalhamos cada um dos componentes.

\subsection{TaPrEC - Tangible Programming Environment for Children}

TaPrEC [Carbajal \& Baranauskas 2016] é um ambiente de programação para crianças, baseado nas TUIs. Permite criar programas de computador organizando objetos tangíveis aplicando três conceitos básicos de programação: sequência, repetição e procedimento. A execução do programa tangível é feita no contexto do ambiente de programação Scratch. TaPrEC possui três componentes (Figura 1a): i) o hardware de baixo custo composto pelo dispositivo Raspberry $P i$, um computador de placa única (SBC - Single-Board Computer) do tamanho de um cartão de crédito e um sistema RFID (Radio-Frequency IDentification) que utiliza um leitor RFID e etiquetas RFID; ii) os blocos de programação são blocos coloridos de madeira semelhantes a peças de quebra-cabeças que contém uma etiqueta RFID (Figura 1b) para que sejam identificados e um símbolo em alto-relevo para representar sua funcionalidade; e iii) o software de controle, desenvolvido na linguagem de programação Scratch, permite processar os programas tangíveis e mostra o resultado da execução no ambiente Scratch. 
VII Congresso Brasileiro de Informática na Educação (CBIE 2018)

Anais do XXIX Simpósio Brasileiro de Informática na Educação (SBIE 2018)

a)
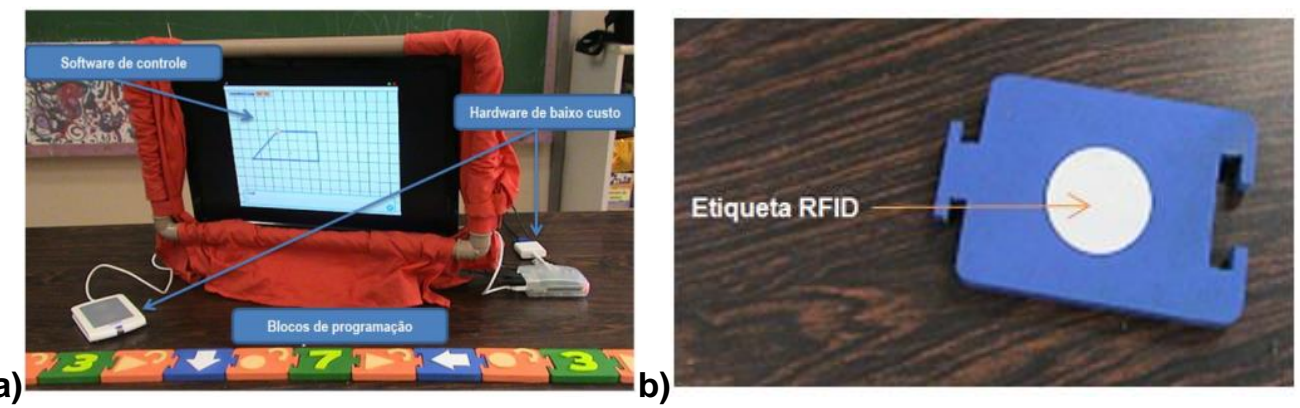

Figura 1. a) componentes do ambiente TaPrEC; b) bloco de programação

\section{$3.2 \mathrm{mBot}$}

mBot é um kit educacional comercial, criado pela empresa MakeBlock, para ensino de robótica, programação e eletrônica para crianças. A versão v1.1 (Figura 2a) tem uma placa mCore (baseada no Arduino UNO) que possui um microcontrolador e dispõe de quatro portas RJ25 para conectar sensores, assim como outras duas portas para conectar motores. Os sensores incluídos na placa mCore são: um sensor de luz, um transmissor Infravermelho, um receptor de Infravermelho, um LED RGV, uma buzina e um botão programável (Figura 2b). Os módulos externos incluídos são: um seguidor de linha, um sensor ultrassônico e um módulo Bluetooth ou Wireless. Uma das formas de controlar e programar o robô é por meio do software mBlock de programação gráfica desenvolvido com base no Scratch.

a)

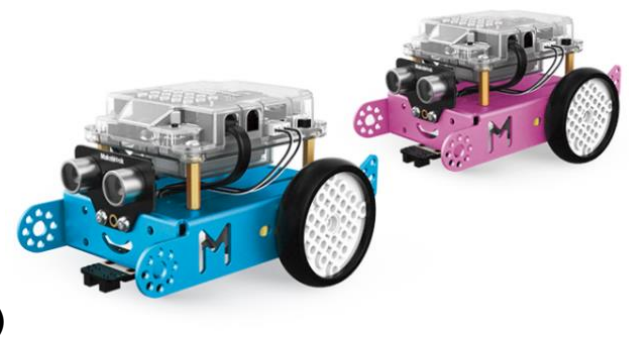

b)

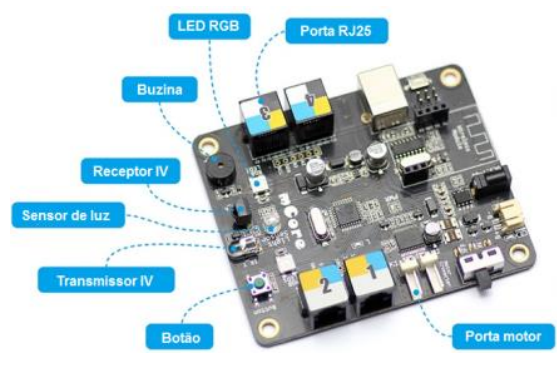

Figura 2. a) kit educacional mBot v1.1; b) sensores incluídos na placa mCore

\section{3 "TaPrEC+mBot": Integração do ambiente TaPrEC e o robô mBot}

Como observamos na Figura 3a, o ambiente "TaPrEC+mBot" possui: i) o sistema RFID do TaPrEC e substituímos o Raspberry PI por um notebook que suporte o software mBlock; ii) os blocos de programação do TaPrEC, e novos blocos para virar o robô para esquerda e direita (Figura 3b); iii) o software de controle que foi atualizado para utilizar as bibliotecas do mBot e precisa ser carregado no ambiente mBlock para permitir a comunicação via Bluetooth entre os blocos de programação e o mBot. A arquitetura do "TaPrEC + mBot" ilustra o funcionamento do ambiente: quando o usuário passa o leitor RFID sobre cada bloco do programa tangível, os identificadores das etiquetas RFID são enviados ao software de controle. O programa principal do software de controle verifica se os identificadores existem na lista de códigos RFID (registrados previamente), se existem são enviados para uma fila de processamento. O programa principal envia para o mBot os comandos associados aos identificadores RFID por meio do Bluetooth e o robô executa a sequência de comandos recebidos. 
a)

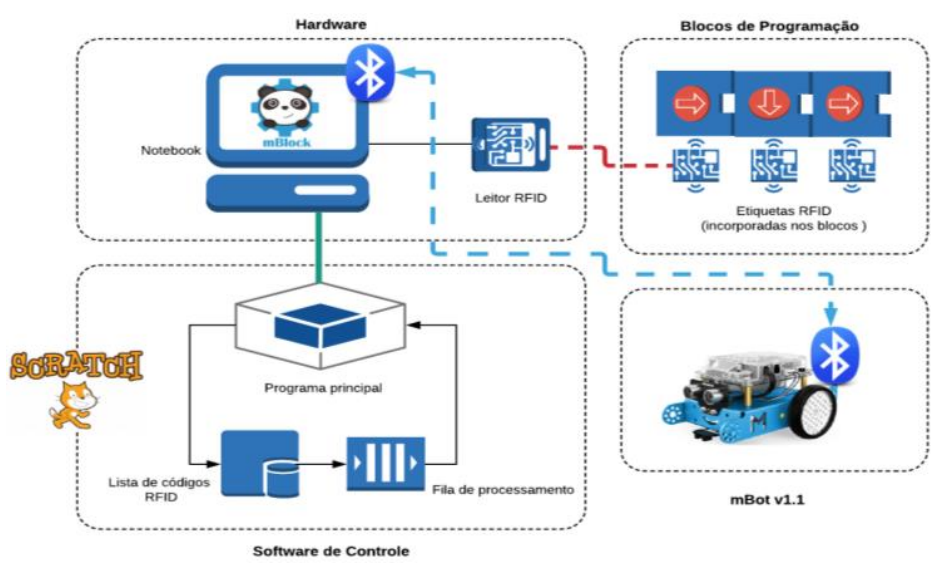

b)

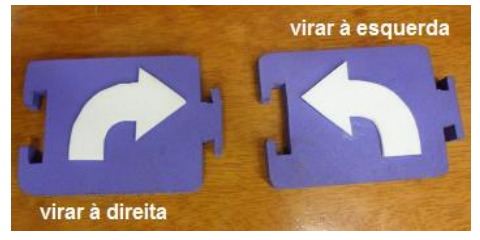

Figura 3. a) arquitetura de "TaPrEC+mBot"; b) blocos para virar o robô

\section{Metodologia}

Realizamos um Estudo de Caso com docentes e estudantes de ensino fundamental com o propósito de explorar a aprendizagem de programação e robótica na escola de forma criativa, assim como avaliar o ambiente "TaPrEC+mBot". As atividades tiveram foco na compreensão de conceitos básicos de programação e a criação de cenários de uso para o ambiente "TaPrEC + mBot" privilegiando o processo de exploração para conseguir que os participantes expressassem ideias criativas. Além disso, utilizamos o formulário da Autoavaliação de emoções (SAM-Self-Assessment Manikin) [Bradley \& Lang 1994] para avaliar a resposta afetiva dos participantes e uma folha de avaliação da oficina para registrar a opinião dos participantes ao finalizar cada encontro.

\subsection{Cenário e participantes}

Ao longo do segundo semestre de 2017, realizamos oficinas no Programa de Integração e Desenvolvimento da Criança e do Adolescente (PRODECAD) que oferece educação suplementar a crianças de 6 a 14 anos matriculadas na EEPG "Sergio Pereira Porto". O PRODECAD funciona dentro do campus da Universidade Estadual de Campinas (UNICAMP), São Paulo. As atividades foram realizadas no espaço "ateliê" e foram agendadas formalmente pela coordenação daquele espaço educativo no conjunto de atividades semanais dos docentes e estudantes envolvidos. Trabalhamos com docentes e estudantes separadamente. No total realizamos seis oficinas (três com as docentes e três com os estudantes) com uma duração de 60 minutos cada. Participaram das oficinas catorze estudantes (entre 8 e 11 anos): cinco mulheres e nove homens; e seis docentes mulheres (entre 40 e 54 anos). A participação dos estudantes foi voluntária.

\subsection{Materiais}

Para a construção dos cenários (circuitos de corrida para o mBot), disponibilizamos para os participantes materiais familiares com representações de objetos do cotidiano, buscando incentivar o pensamento a respeito de novas possibilidades de seus usos em diferentes contextos. Os materiais permitiram a criação de cenários fáceis reorganizando-os. Na Figura 4 observamos os materiais disponibilizados: a) uma rampa de papelão, b) sinais de trânsito, c) árvores de E.V.A, d) uma casinha de papelão. Na fase da construção dos circuitos de corrida, os participantes escolhiam os materiais que utilizariam, não era obrigatório utilizar todos. 
VII Congresso Brasileiro de Informática na Educação (CBIE 2018)

Anais do XXIX Simpósio Brasileiro de Informática na Educação (SBIE 2018)

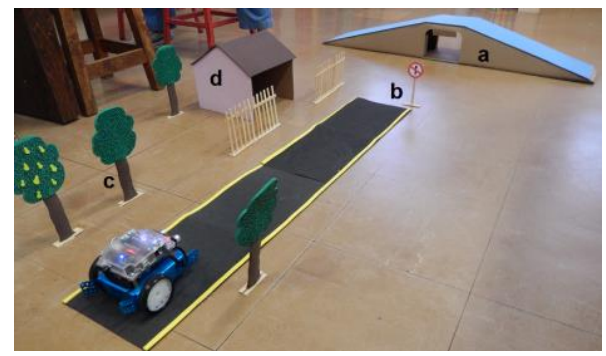

Figura 4. Materiais utilizados nas oficinas

\subsection{Dinâmica das oficinas}

Em cada encontro os participantes trabalhavam em equipes para resolver tarefas simples de deslocamento do robô mBot aplicando conceitos básicos de programação. Filmamos as oficinas com a permissão da instituição, professores e adultos responsáveis de cada estudante participante do projeto. Utilizamos esses vídeos para observar a interação dos participantes com o ambiente "TaPrEC + mBot" e o processo criativo dos circuitos de corrida. Ao finalizar cada encontro os participantes preenchiam o formulário da Autoavaliação de emoções e a folha de avaliação.

\section{Resultados das Oficinas}

As oficinas objetivaram formar os participantes na utilização do ambiente "TaPrEC + mBot" de forma a que criassem seus próprios cenários de uso do ambiente. Os participantes planejaram circuitos de corrida para o mBot numa folha de papel; depois montaram o circuito utilizando os materiais disponibilizados e finalmente criaram programas tangíveis para que o mBot percorresse o circuito. Agrupamos os resultados obtidos da seguinte maneira:

\subsection{Criação de cenários para programação tangível}

No caso das docentes, durante o planejamento, primeiro pensaram no tema que queriam ensinar aos seus estudantes e depois construíram um mapa do circuito de corrida (Figura 5a) e registraram as regras da atividade proposta (por exemplo: "os grupos [de crianças] perderiam pontos ao não respeitar os sinais de trânsito", "a pontuação será de acordo com o melhor tempo de percurso entre os participantes”). Durante a montagem dos cenários, as equipes utilizaram todos os materiais disponibilizados (Figura 5b). As docentes criaram circuitos de corrida para o mBot articulando objetivos pedagógicos como por exemplo a lateralidade, o ensino de sinais de trânsito, a contação de histórias.

a)

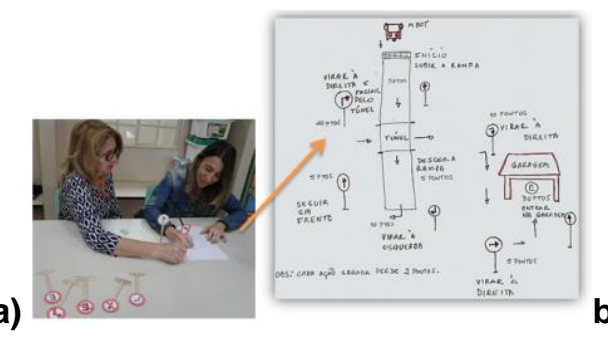

b)

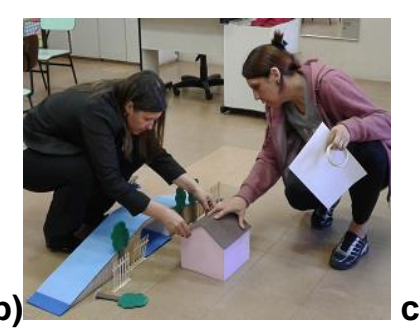

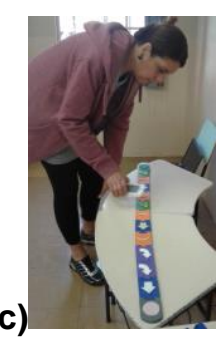

Figura 5. Processo de criação das docentes: a) planejamento do circuito de corrida; b) montagem do circuito; c) criação de programas tangíveis

No caso dos estudantes, formaram quatro equipes para planejar seu circuito de corrida (Figura 6a). Ao revisar os mapas dos circuitos notamos que três equipes utilizaram a 
VII Congresso Brasileiro de Informática na Educação (CBIE 2018)

Anais do XXIX Simpósio Brasileiro de Informática na Educação (SBIE 2018)

casa de papelão e a rampa; e uma equipe utilizou a casa e os sinais de trânsito e nenhuma equipe utilizou as árvores de E.V.A. Os circuitos de corrida planejados (Figura 6b) foram desafiadores na hora de montar os programas tangíveis para que o mBot realizasse o percurso.
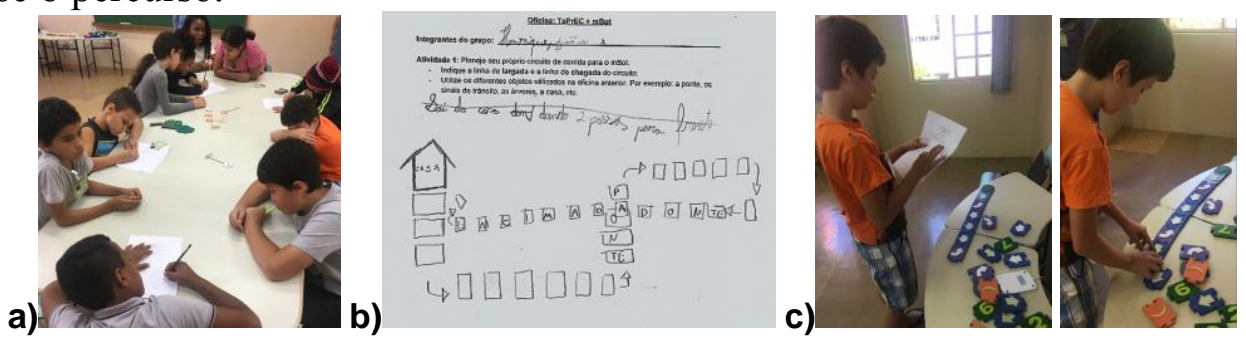

Figura 6. Processo de criação dos estudantes: a) planejamento do circuito de corrida; b) mapa do circuito; c) criação dos programas tangíveis

\subsection{Criação de programas tangíveis}

Os participantes criaram vários programas tangíveis (Figuras $5 \mathrm{c}$ e $6 \mathrm{c}$ ) utilizando conceitos básicos de programação (sequência e repetição) para conseguir que o mBot percorresse seu circuito de corrida. Observamos que os participantes encararam situações de correção de erros até alcançar o objetivo estabelecido: revisavam se a solução em papel coincidia com o programa tangível, acompanhavam os movimentos do mBot e recalculavam o quantidade de blocos de deslocamento. Durante esse processo os participantes conversavam e davam sugestões para corrigir o programa tangível.

\subsection{Resultados da Autoavaliação de emoções}

Utilizamos o formulário da Autoavaliação de emoções (SAM - Self-Assessment Manikin) [Bradley \& Lang 1994] para que os participantes avaliassem sua resposta afetiva à experiência na oficina. As escalas estão relacionadas a várias figuras expressivas de bonecos (manikins) ao longo de três dimensões afetivas (Figura 7): satisfação (ou pleasure), motivação (ou arousal), e controle (ou dominance). Na dimensão de satisfação (primeira linha), a escala varia de um boneco feliz e sorridente a um boneco triste. Na dimensão de motivação (segunda linha), varia de uma figura animada com os olhos abertos até uma figura sonolenta. A dimensão de controle (terceira linha) representa o domínio sobre o objeto ou situação e está propositalmente apresentada na ordem inversa das dimensões anteriores, isto é do menor controle da situação ao maior controle. Cada dimensão afetiva tem uma escala de 9 pontos representados por círculos e os participantes tinham de marcar apenas um ponto por dimensão. Neste trabalho o método de análise dos resultados foi o seguinte: os valores 9, 8 e 7, representam uma resposta afetiva positiva; os valores 6,5 e 4, representam uma resposta afetiva neutra; e os valores 3,2 e 1, representam uma resposta afetiva negativa.

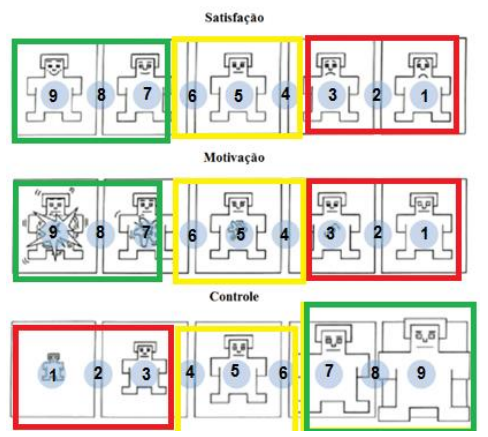

Figura 7. Formulário da Autoavaliação de emoções [Bradley \& Lang 1994] 
VII Congresso Brasileiro de Informática na Educação (CBIE 2018)

Anais do XXIX Simpósio Brasileiro de Informática na Educação (SBIE 2018)

$\mathrm{Na}$ Figura 8 apresentamos os resultados das respostas afetivas dos estudantes. Observamos que para as três oficinas, a satisfação e a motivação tiveram avaliações positivas pela maior parte dos estudantes. Em relação ao controle, que indica o domínio dos participantes em relação ao sistema, os resultados são mais diversos, no entanto a maior parte dos resultados encontra-se na parte positiva da escala.

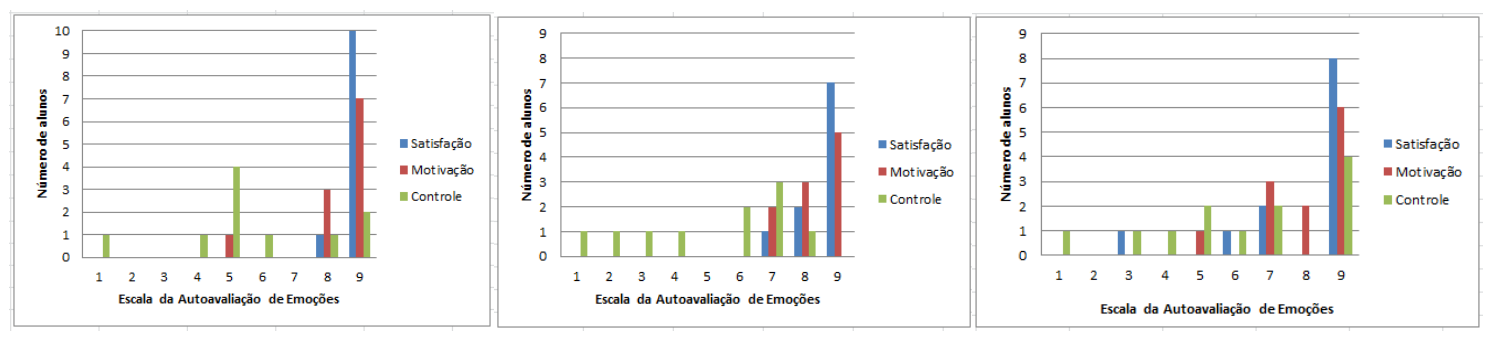

Figura 8. Resultados Autoavaliação de emoções - estudantes

$\mathrm{Na}$ Figura 9 apresentamos os resultados das respostas afetivas das docentes. Devemos esclarecer que as oficinas 2 e 3 foram complementares então realizamos apenas uma avaliação para ambas as oficinas. Observamos que para as dimensões afetivas de satisfação e motivação, os resultados encontram-se na parte positiva da escala. Para o caso do controle, a maior parte dos resultados encontra-se na parte positiva da escala. Observamos que uma professora avaliou negativamente a dimensão de controle, mas sua motivação e satisfação foram positivas.

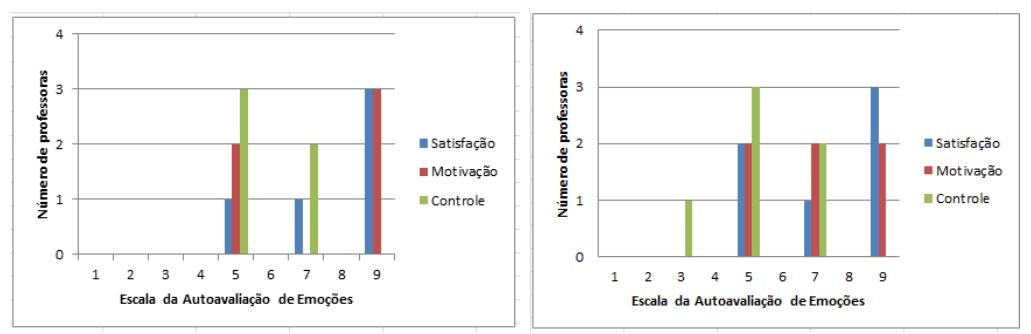

Figura 9. Resultados Autoavaliação de emoções - docentes

\section{Discussão}

Ao observar as atitudes e comentários dos estudantes durante as oficinas, percebemos que se mostraram motivados com a utilização do mBot e não tiveram maiores dificuldades com a manipulação dos blocos de programação. Notamos que se sentiram especialmente envolvidas e engajadas quando cada equipe criou seu próprio circuito de corrida. Por outro lado, demonstraram dificuldades para calcular a quantidade de blocos de deslocamento necessários para que o mBot percorresse seu circuito de corrida. Isto causou diferentes reações por parte dos estudantes: alguns se sentiram desafiados e com mais vontade de criar estratégias para completar o percurso (por exemplo, testar seu programa tangível por partes); outros estudantes ficaram um pouco desapontados, mas continuaram tentando porque queriam "ganhar" das outras equipes. Em ambos os casos, as equipes corrigiram várias vezes seu programa tangível. Observamos que os estudantes idearam formas criativas para calcular a quantidade de movimentos necessários para completar o percurso. Por exemplo, um aluno simulou o percurso do mBot agindo como se fosse o próprio robô, realizou o percurso dando pequenos passos, enquanto outro membro da equipe contava o número de passos que estava dando (Figura 10). Isto ajudou a sua equipe para criar corretamente seu programa tangível e foram os primeiros em completar o circuito de corrida corretamente. 


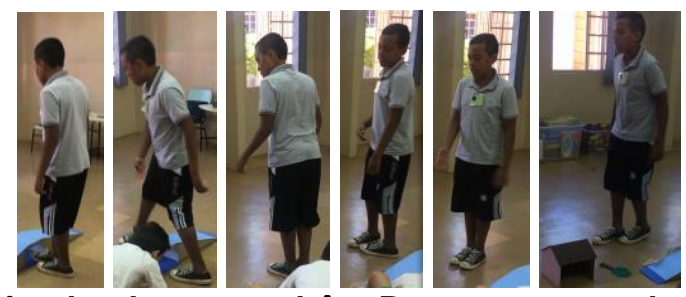

Figura 10. Criança simulando ser o robô mBot e percorrendo o circuito de corrida

Identificamos que os movimentos do mBot são um pouco imprecisos dependendo da superfície onde se desloca (por exemplo a superfície da rampa feita com E.V.A.). Uma docente comentou isso na folha de avaliação dizendo "não gostei de falta de precisão do carro". Para resolver esse problema fizemos ajustes no software de controle para aumentar a velocidade do robô para conseguir movimentos mais precisos em superfícies que não são lisas como é o caso do E.V.A. Neste estudo buscamos fazer com que as docentes planejassem e experimentassem suas próprias atividades de maneira que articulassem a programação e a robótica proporcionada pelo ambiente "TaPrEC $+\mathrm{mBot}$ " com objetivos pedagógicos. Durante o planejamento das atividades, as docentes incluíram temas como a lateralidade, ensino dos sinais de trânsito e a contação de histórias. Alguns comentários das docentes com relação à pergunta da folha da avaliação: "O que mais gostou da oficina e do sistema?" foram: "gostei do aspecto lúdico e criativo da oficina", "gostei do sistema por não ser muito complexo...", "gostei do sistema porque não é muito complicado para as crianças", "gostei do desafio em forma de brincadeira", "gostei dos materiais oferecidos". Diversos comentários similares foram expressos na folha de avaliação, o que sugere abertura das docentes para trabalhar com o ambiente "TaPrEC+mBot".

\section{Considerações finais}

A aprendizagem criativa é um conceito que busca entender, experimentar e caracterizar metodologias e ambientes de aprendizagem capazes de promover a criatividade. Neste trabalho buscamos explorar o conceito da aprendizagem criativa com docentes e estudantes por meio da criação de um cenário simples de uso para o ambiente "TaPrEC $+\mathrm{mBot}$ " (um circuito de corrida para o robô $\mathrm{mBot}$ ). As atividades realizadas com as docentes reforçaram a importância do envolvimento dos educadores no planejamento de atividades significativas que fomentem o pensamento criativo dos estudantes. Também foi essencial valorizar a opinião das docentes sobre como novas ferramentas tecnológicas podem ser incorporadas na sala de aula e como o fariam. Observamos que para os estudantes o processo de criação de seus próprios cenários para o ambiente "TaPrEC + mBot" foi bastante empolgante e, ao mesmo tempo, montar os programas tangíveis para controlar o robô foi desafiador devido à complexidade dos cenários. Durante a realização de atividades notamos a importância de ter um espaço amplo para que os estudantes trabalhem e espalhem o material e consigam "brincar" e experimentar; comportamentos criativos emergem da exploração ativa e da experimentação. Como trabalhos futuros esperamos realizar estudos com novos cenários utilizando o ambiente "TaPrEC + mBot", explorando os sensores do mBot.

\section{Agradecimentos}

À CAPES (\#1545149/2015 e \#1654045/2016), ao CNPq (\#306272/2017-2) e à FAPESP (\#2015/16528-0) pelo apoio financeiro concedido no desenvolvimento deste trabalho.

\section{Referências}


VII Congresso Brasileiro de Informática na Educação (CBIE 2018)

Anais do XXIX Simpósio Brasileiro de Informática na Educação (SBIE 2018)

Avila, C., Cavalheiro, S., Bordini, A., \& Marques, M. (2017, October). O Pensamento Computacional por meio da Robótica no Ensino Básico-Uma Revisão Sistemática. In Brazilian Symposium on Computers in Education (Simpósio Brasileiro de Informática na Educação-SBIE) (Vol. 28, No. 1, p. 82).

Benitti, F. B. V. (2012). Exploring the educational potential of robotics in schools: A systematic review. Computers \& Education, 58(3), 978-988.

Bradley, M. M., \& Lang, P. J. (1994). Measuring emotion: the self-assessment manikin and the semantic differential. Journal of behavior therapy and experimental psychiatry, 25(1), 49-59.

Bruner, J. S., Olver, R. R., \& Greenfield, P. M. (1966). Studies in cognitive growth.

Carbajal, M. L. \& Baranauskas, M. C. C. (2016). Evolução de um ambiente para programação tangível e avaliação de seu uso em cenário educacional. In Nuevas Ideas en Informática Educativa, Volumen 12, p. 666 - 671.

Clements, D. H. (1999). The future of educational computing research: The case of computer programming. Information Technology in Childhood Education Annual, 1999(1), 147-179.

Horn, M. S., \& Jacob, R. J. (2007, April). Tangible programming in the classroom with tern. In CHI'07 extended abstracts on Human factors in computing systems (pp. 19651970). ACM.

Iba, T., \& Miyake, T. (2010, March). Learning Patterns: a pattern language for creative learning II. In Proceedings of the 1st Asian Conference on Pattern Languages of Programs (p. 4). ACM.

Ishii, H., \& Ullmer, B. (1997, March). Tangible bits: towards seamless interfaces between people, bits and atoms. In Proceedings of the ACM SIGCHI Conference on Human factors in computing systems (pp. 234-241). ACM.

McNerney, T. S. (1999). Tangible programming bricks: An approach to making programming accessible to everyone (Doctoral dissertation, Massachusetts Institute of Technology).

Resnick, M. (2006). Computer as paint brush: Technology, play, and the creative society. Play= learning: How play motivates and enhances children's cognitive and socialemotional growth, 192-208.

Sefton-Green, J., \& Bresler, L. (2011). Theories and histories: Creative learning and its contexts. The Routledge international handbook of creative learning, 9-14.

Sipitakiat, A., \& Nusen, N. (2012, June). Robo-Blocks: designing debugging abilities in a tangible programming system for early primary school children. In Proceedings of the 11 th International Conference on Interaction Design and Children (pp. 98-105). ACM.

Stewart, J., Stewart, J. R., Gapenne, O., \& Di Paolo, E. A. (Eds.). (2010). Enaction: Toward a new paradigm for cognitive science. MIT Press.

Varela, F. J., Thompson, E., \& Rosch, E. (2017). The embodied mind: Cognitive science and human experience. MIT press.

Xu, D. (2005). Tangible user interface for children-an overview. In Proc. of the UCLAN Department of Computing Conference.

https://www.makeblock.com/steam-kits/mbot (ultimo acesso em junho de 2018) 